\title{
Bank Customers' Decision-Making Process in Choosing between Ethical and Conventional Banking: A Survey-Based Examination
}

\begin{abstract}
Despite the movement of sustainable consumerism during the last years as well as the crisis of trust evoked by the financial crisis of 2008, ethical banks' market shares remain humble. This study applies models of ethical decision-making to investigate customers' reasons to prefer conventional over ethical banks. First, a model of bank customers' ethical decision-making process in choosing between ethical and conventional banking is set up based on multiple established models from literature. Second, the theoretical model is assessed via data from an online-survey using partial least squares structural equation modelling. Main factors hindering potential customers to switch to ethical banks are missing information, low pressure of the social context, low moral intensity, and a perceived disadvantageous economic effect. However, a good reputation of ethical banks, high concern for the topic, and low scepticism indicate a positive general opinion of ethical banking. These results suggest that more factual information and emotional charging of ethical banking would strengthen demand. On the theoretical side, our analysis shows how to contextualize general models of ethical decision-making to a specific domain and it suggests that the integration of multiple established ethical decision-making models is sensible. Further we suggest that reputation and economic benefit - which we included as domainspecific extensions of established ethical decision-making models - are concepts to consider for a general domain-independent extension of ethical decision-making models.
\end{abstract}

Keywords: customer behavior, bank selection criteria, ethical decision-making, ethical banking, sustainable banking 